\title{
Comparative study of the effect of bFGF and plasma rich in growth factors on cryopreserved multipotent mesenchymal stromal cells from bone marrow and tendon of rats
}

\author{
Volkova N. A., Yukhta M. S., Goltsev A. N. \\ Institute for Problems of Cryobiology and Cryomedicine of the National Academy of Sciences of Ukraine, Kharkiv, Ukraine \\ e-mail:volkovana781@gmail.com
}

\section{ABSTRACT}

THE PURPOSE of study was to investigate in vitro effects of growth factors, known as cell proliferation stimulants, to determine the most suitable agent for enhancing the proliferation and migration activity of cryopreserved multipotent mesenchymal stromal cells (MMSCs) derived from bone marrow and tendon tissue.

\begin{abstract}
MATERIALS AND METHODS. MMSCs were obtained from bone marrow and tendon tissues of rats. Cryopreservation was carried out under the protection of $10 \%$ DMSO with the addition of $20 \%$ fetal bovine serum at a cooling rate of $1^{\circ} \mathrm{C} / \mathrm{min}$ to $-80^{\circ} \mathrm{C}$ and subsequent freeze in liquid nitrogen. During the cultivation of the cryopreserved MMSCs, basis fibroblast growth factor (bFGF) and plasma rich in growth factors were used. The ability to proliferation (MTT assay), migration (in vitro scratch assay), and the synthesis of collagen type I (immunocytochemical study of collagen type I expression) were evaluated.
\end{abstract}

RESULTS. The use of plasma rich in growth factors contributes to increasing the ability of cryopreserved MMSCs from bone marrow to proliferate and migrate, associated with decreasing in the relative number of cells that express collagen type I. Cultures of cryopreserved MMSCs from the tendon tissue exhibit greater sensitivity to the bFGF compared to the plasma rich in growth factors that have a manifestation in the increasing of cell proliferation and migration ability.

CONCLUSIONS. bFGF and plasma rich in growth factors can be used as stimulants for stromal cell cultures.

KEYWORDS: multipotent mesenchymal stromal cells; bone marrow; tendon tissue; basic fibroblast growth factor; plasma rich in growth factors

Reparative regeneration processes in the tendons require much more time than in other connective tissues, which is due to their hypoxic and hypovascular structure [1]. Therefore, the development of new biotechnological approaches aimed at accelerating the recovery of the tendons will contribute to reducing the temporal disability and reduce the disability of patients after injuries of the musculoskeletal system.

Today, one of the effective tools for regenerative medicine is the use of growth factors produced by many cells, as well as in vitro cultured cells themselves, including multipotent mesenchymal stromal cells (MMSCs). Isolation and cultivation of cells of mesenchymal origin from organs and tissues is the first stage of obtaining material for the use in regenerative medicine for the treatment of pathologies of various genesis: diseases of the musculoskeletal system, neurological, gynecological, cardiovascular diseases, etc. [2-5]. In addition, the immunomodulatory properties of mesenchymal cells can be used for autoimmune diseases [6] and for immune correction in transplantology [7].

MMSCs can promote regeneration not only through direct cell differentiation, but also via secretion of growth factors, which are among the most important multifunctional molecules involved in regeneration [8-10]. For example, family of fibroblast growth factors (FGF) are one of the key factors that can contribute to the restoration of biomechanical and histological properties of damaged tendons [11]. Other cytokines 
also enhance the regeneration of tendons: transforming growth factor- $\beta$ (TGF- $\beta$ ), basic fibroblasts growth factor (bFGF), platelet-derived growth factor (PDGF), insulin-like growth factor (IGF-1), epidermal growth factor (EGF) and vascular endothelial growth factor (VEGF) [12].

However, in order to enhance the effect of MMSCs in vivo and in vitro (accelerating the rate recovery of tissue, cell proliferation and migration), additional components, in particular, the indicated growth factors are necessary. One of their main sources in the body is the blood from which modern biotechnological methods can obtain various products: L-PRP (leucocyte and platelet-rich plasma; P-PRP (pure platelet-rich plasma; P-PRF (pure platelet-rich fibrin); L-PRF (leucocyte and platelet-rich fibrin) $[13,14]$. All of these derivatives contain a different ratio of growth factors: hepatocyte growth factor (HGF), TGF- $\beta$, PDGF, IGF-1, VEGF, EGF, thrombospondin $1[15,16]$. That is why these preparations have been widely used in regenerative medicine.

The use of plasma rich in growth factors (PRGF) derived from P-PRP in modification [17] contributes to the restoration of tendon and cartilage tissue $[18,19]$. In addition, it is known that bFGF and PRGF are capable of stimulating the proliferation of MMSCs and regulating their differentiation into tenocytes [20]. In recent years, more in-depth studies of PRGF have led to the discovery of a much more complex system of interactions between the factors involved in it and the cells or target tissues they are exposed to [21, 22]. These factors are responsible for complex signals not only in the system of intercellular interactions, but also serve as an intermediate link between hormones and cytokines.

In the previous work, we investigated the morpho-functional characteristics of cryopreserved MMSCs derived from bone marrow, adipose and tendon tissues, and found that MMSCs of the tendon tissue (TT-MMSCs) were characterized by greater colony-formation, proliferation, and lower directed differentiation potency than MMSCs from bone marrow and adipose tissue [23].

In order to provide a basis for further research in the field of regenerative medicine, an in vitro study of the effects of the growth factors bFGF and PRGF, known as cell proliferation inductors has been carried out. It was aimed to determine the most suitable agent for enhancing the proliferative and migration activity of MMSCs obtained from the bone marrow or tendon tissue and the subsequent development of an experimental evaluation system for selecting the optimal cell source for the treatment of musculoskeletal tissues injuries.

According to the literature data, the bFGF content in the PRGF has a low concentration compared with other growth factors, which is insufficient to enhance the proliferative activity of cells, if we consider this factor separately [18]. However, the growth factors that are part of the PRGF, depending on the dose, can multiply the effect of each other and act synergistically [22]. In the present in vitro study, we used the autologous system of PRGF and MMSCs to support further in vivo studies. In addition, bFGF at concentration of $15 \mathrm{ng} / \mathrm{ml}$ was used as an inductor of MMSCs proliferative activity $[11,20]$.

The PURPOSE of the study was to investigate in vitro effects of bFGF and PRGF on proliferative and migration activity of cryopreserved MMSCs derived from bone marrow and tendon tissue.

\section{MATERIALS AND METHODS}

All manipulations with animals were carried out in accordance with the international principles of bioethics and in compliance with the Law of Ukraine «On the Protection of Animals from Cruelty» (2006), «European Convention for the Protection of Vertebrate Animals Used for Experimental and Other Scientific Purposes» (Strasbourg, 1986). [24].

\section{OBTAINING AND CULTURE OF MIMSCS FROM BONE}

\section{MARROW AND TENDON TISSUE.}

MMSCs from bone marrow (BM-MMSCs) were obtained from femurs of rats weighting 100-150 $\mathrm{g}(\mathrm{n}=7)$. The cells were collected by washing of resected bone fragments (3-4 $\mathrm{mm}$ ) with Hanks solution followed by passing through the needle with a decreasing diameter. The next step included centrifugation at $1500 \mathrm{rpm}$ for 5 minutes. The resulting cell suspension was plated into $25 \mathrm{~cm}^{2}$ culture flasks (PAA, Austria) at concentration $10^{3}$ cells $/ \mathrm{cm}^{2}$.

The primary suspension of cells from the tendon tissues was obtained from bioptates by enzymatic digestion. For this, tissue samples were washed with Hanks solution (PAA, Austria) with $150 \mu \mathrm{g} / \mathrm{ml}$ gentamicin (Farmak, Ukraine) and incubated in $1.5 \mathrm{mg} / \mathrm{ml}$ collagenase type II (PanEco, Russia) at $37^{\circ} \mathrm{C}$ for 18 hours. Cells were isolated by resuspending followed by centrifugation at $1500 \mathrm{rpm}$ for $3 \mathrm{~min}$. A culture medium was added to the pellet and seeded into a culture flask at density $1 \cdot 10^{4} \mathrm{cells} / \mathrm{cm}^{2}$

The complete growth medium in all cases consisted of IMDM medium (PAA, Austria), $10 \%$ of the fetal bovine serum (FBS) (HyClone, USA), $150 \mu \mathrm{g} / \mathrm{ml} \mathrm{kanamycin} \mathrm{(Farmak,} \mathrm{Ukraine)} \mathrm{and} 5 \mu \mathrm{g} / \mathrm{ml}$ amphotericin $\mathrm{B}$ (PAA, Austria). The culture medium was changed every 3 days. The standard cultivation conditions in a $\mathrm{CO}_{2}$-incubator at $37^{\circ} \mathrm{C}$ in an atmosphere of $5 \% \mathrm{CO}_{2}$ (Sanyo, Japan) were used in the study. Upon reaching the monolayer, the cells were subcultured using $0.25 \%$ trypsin solution and Versene solution in the ratio 1:1.

CRYOPRESERVATION OF MIMSCs. Cryopreservation of MMSCs cultures was carried out under the protection of $10 \%$ of DMSO (PanEco, Russia) with an addition of $20 \%$ FBS. Cryoprotector solution was prepared on a nutrient medium. The resulting suspensions were placed in $1 \mathrm{ml} \mathrm{Nunc}{ }^{\circledR}$ cryovials (Thermo Scientific, USA). The cooling rate was $1{ }^{\circ} \mathrm{C} / \mathrm{min}$ to $-80^{\circ} \mathrm{C}$, followed by storage in liquid nitrogen [25]. The thawing was performed in a water bath at $40{ }^{\circ} \mathrm{C}$ until a liquid phase appeared. The removal of the cryoprotectant was carried out by adding Hanks solution (PAA, Austria) at 1:9 ratio followed by centrifugation at $1500 \mathrm{rpm}$ for 5 minutes. When culturing the studied cells after cryopreservation, the same conditions were used as for primary cultures.

OBTAINING PLASIMA RICH IN GROWTH FACTORS. Whole blood $(2 \mathrm{ml})$ was collected from the rat's tail vein, and then centrifuged in a sterile tube for 8 minutes at $1500 \mathrm{rpm}$. After layer stratification of blood by centrifugation, a layer of plasma rich in growth factors $(0.2 \mathrm{ml})$ was aspirated directly over a layer of leukocytes under sterile conditions using an insulin syringe according to the standard procedure [17].

APPLICATION OF GROWTH FACTORS IN THE CULTURE OF CRYOPRESERVED MIMSCs. To determine the effect of recombinant bFGF protein (Sigma-Aldrich, USA) on morphological and proliferative characteristics of cryopreserved MMSCs, they were cultured for 10 days. The nutrient medium consisted of IMDM, $10 \%$ FBS, $15 \mathrm{ng} / \mathrm{ml}$ bFGF [11, $20,26]$. The control samples were cryopreserved cultures of MMSCs, cultivated without factor use.

To determine the effect of PRGF on morphological and proliferative characteristics of cryopreserved MMSCs, cultivation was performed for 10 days. The nutrient medium consisted of IMDM, $10 \%$ PRGF. Control samples were cultures of cryopreserved MMSCs cultivated without PRGF.

ANALYSIS OF MIMSCS PROLIFERATION. In the studied cultures of MMSCs of bone marrow and tendon tissue, with or without growth factors, the proliferative activity was determined at 1, 3, 7, 10 days in culture using the MTT assay [27]. Measurement of the optical density of the formazan solution in the supernatant was performed on photo colorimeter KFK-2-UHL4.2 at $540 \mathrm{~nm}$. As a control, a culture medium without cells was used.

ANALYSIS OF MIMSCS MIGRATION (IN VITRO SCRATCH ASSAY). The ability of MMSCs to migrate was determined by the rate of healing pattern of a defect in cell monolayer. For this, MMSCs in the amount of $1.5 \cdot 10^{3} \mathrm{cells} / \mathrm{cm}^{2}$ were seeded in 6 -well plates and cultured for 10 days until the confluent was formed, and then a scratch of a monolayer (defect size of $20 \times 10 \mathrm{~mm}$ ) was performed using a plastic scraper. On the $4^{\text {th }}$ and $7^{\text {th }}$ days, cell cultures were fixed in a $4 \%$ paraformaldehyde solution followed by staining with azur-II and eosin (Romanowsky-Giemsa stain). 
A light microscope was used to count the number of cells in the defect zone per $1 \mathrm{~cm}^{2}$ of area.

ANALYSIS OF COLLAGEN TYPE I EXPRESSION. The staining of MMSCs colonies for collagen type I was carried out using monoclonal antibodies to COL-1 (Sigma-Aldrich, USA, Cat. No. C2456) at 1:2000 and CFTM488A (Sigma-Aldrich, USA, Cat. No. SCJ4600014) according to the manufacturer's instructions. Paraformaldehyde-methanol fixation of cell cultures was used. Fluorescence microscopy was performed using a confocal scanning microscope LSM 510 Meta (Carl Zeiss, Germany). The samples were further stained with a luminescent dye DAPI (Sigma, USA) at $1 \mu \mathrm{g} / \mathrm{ml}$ for $30 \mathrm{~min}$ to visualize cell nuclei.

STATISTICAL ANALYSIS. Statistical data analysis was performed using MS Office Excel 2007 (Microsoft, USA) and Statistika 8 (StatSoft Inc., USA) software. At the normal distribution of variables, the significance of difference between groups was evaluated using Student's t-test. The results are presented as a mean and standard error $(\mathrm{M} \pm \mathrm{m})$; differences are significant at $p \leq 0.05$.

\section{RESULTS AND DISCUSSION}

\section{PROLIFERATIVE ACTIVITY OF CRYOPRESERVED MMSCs}

\section{OF BONE MARROW OR TENDON TISSUE UNDER}

\section{THE INFLUENCE OF bFGF OR PRGF.}

When culturing cryopreserved BM-MMSCs with bFGF and PRGF, the growth pattern was similar, but cell growth was significantly higher with the application of PRGF on the $3^{\text {rd }}$ and $7^{\text {th }}$ days compared to bFGF (Fig. 1). On the $7^{\text {th }}$ day of cultivation of BM-MMSCs with PRGF, cell growth was 2.3 times higher, with bFGF applied - 1.5 times as much as control. On the $10^{\text {th }}$ day in culture BM-MMSCs with PRGF, the cell growth was above 1.3 times, the application of bFGF - 1.2 times compared to the control.

The proliferative activity of cryopreserved TT-MMSCs with bFGF was significantly increased by 1.2 times on the $7^{\text {th }}$ day and 1.3 times by on the $10^{\text {th }}$ day of cultivation compared with the control (Fig. 2). The use of the PRGF did not lead to significant changes in the investigated index for control.

Thus, the use of the bFGF and PRGF in culture of the studied cells resulted in a significant increase in their proliferative activity. Our results are consistent with those of other authors [28], which show that bFGF is a powerful angiogenesis stimulator and a regulator of cell migration and proliferation, which provides a precondition for application this growth factor as a therapeutic agent to improve the recovery of damaged tissues.

\section{MIGRATORY ACTIVITY OF CRYOPRESERVED MIMSCS \\ FROM BONE MARROW OR TENDON TISSUE UNDER \\ THE INFLUENCE OF bFGF OR PRGF.}

The migration ability of cells has a direct impact on the efficiency, character and rate of damaged tissue regeneration. The rate of migration depends on the properties of the cells itself, and on the microenvironment, they are located in. Therefore, the next stage of the study was the study of migratory activity of cryopreserved MMSCs of bone marrow and tendon tissue by determining the rate of healing a defect of a monolayer during cultivation.

The obtained results (Fig. 3) indicated a probable increase in the density of cells in the defect area when cultivated the BM-MMSCs with the PRGF 1.6 times on the $4^{\text {th }}$ day and 1.4 times on the $7^{\text {th }}$ day with respect to control. The use of bFGF also increased the migratory activity of the BMMMSCs on the $7^{\text {th }}$ day of observation by 1.4 times compared to control. There were no significant differences between the groups with application of bFGF or PRGF on the $7^{\text {th }}$ day.

The results of determining the migration activity of TT-MMSCs with the application of bFGF or PRGF are shown in Fig. 4. On the $4^{\text {th }}$ day, no significant differences were found between the groups using $b F G F$ and SFRF respecting control. The application of bFGF on the $7^{\text {th }}$ day resulted in a significant increase in relative number of cells by 1.2 times in comparison with control.

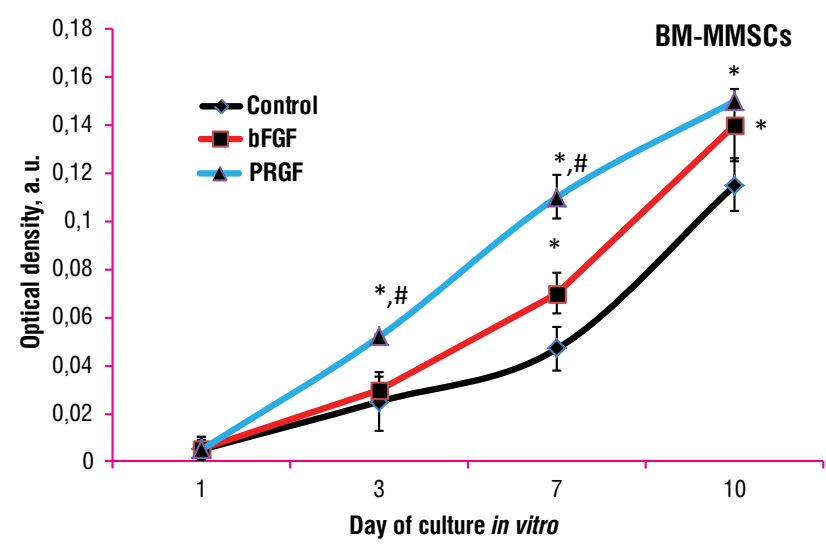

Fig. 1. Optical density of the culture medium, as a results of the MTT assay in the dynamics of cultivation of cryopreserved BM-MMSCs with the bFGF or PRGF $(n=6, M \pm m)$.

Notes: * - differences are significant compared to control group; $p$ $<0.05$; \# - differences are significant compared to bFGF application group, $p<0.05$.

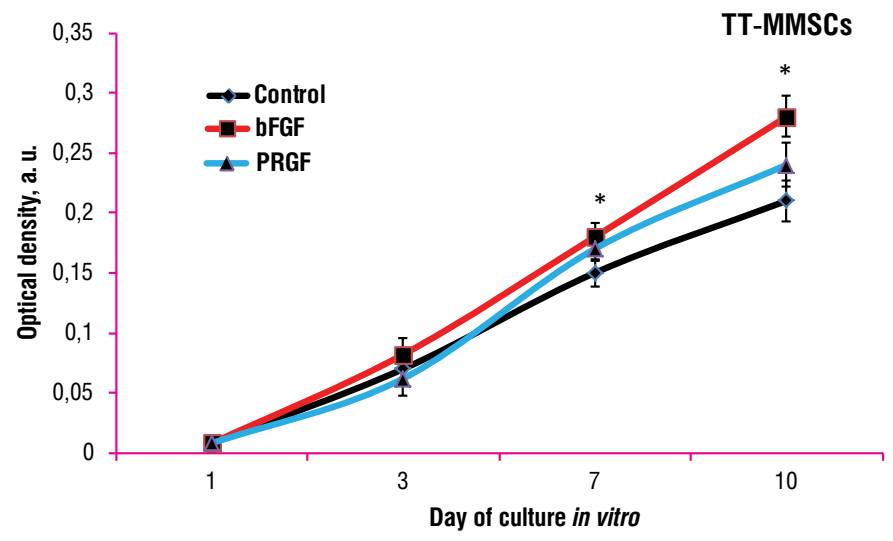

- Fig. 2. Optical density of the culture medium, as a results of the MTT assay in the dynamics of cultivation of cryopreserved TT-MMSCs with the bFGF or PRGF $(n=6, M \pm m)$.

Note: * - differences are significant compared to control group, $p<0.05$.

\section{SYNTHESIS OF COLLAGEN TYPE I OF CRYOPRESERVED MMSCS OF BONE MARROW OR TENDON TISSUE UNDER THE INFLUENCE OF bFGF OR PRGF.}

The culture of BM-MMSCs was characterized by the presence of spindle-shaped and sail-shaped cells, $89.6 \pm 2.7 \%$ of which were positively stained for collagen type I (Fig. 5). In the case of bFGF application, the number of cells expressed collagen type I was $90.4 \pm$ $3.2 \%$. At the application of PRGF, there was a decrease in the relative number of collagen-positive cells $(74.2 \pm 2.7 \%, p<0.05)$, which is probably due to increased proliferative activity of the cells, which lead to reduction of collagen genes expression [29].

TT-MMSCs during cultivation had spindle-shaped and triangularshape forms with a homogeneous cytoplasmic density. The relative number of cells which synthesized collagen type I in the control was $73.4 \pm 2.5 \%$. Addition of bFGF did not lead to a significant change in the relative number of cells $(73.2 \pm 1.5 \%)$. The application of PRGF resulted in an increase in the relative number of cells that were positively stained for collagen type I $(82.1 \pm 3.6 \%, p<0.05)$.

Obtaining a therapeutic dose of cells to repair damaged tissue requires multiplication of stem cells in the culture. Cultivation is a time-dependent process, which is a limiting factor at the stage of cell therapy. The improving of cell proliferation while preserving their basic 


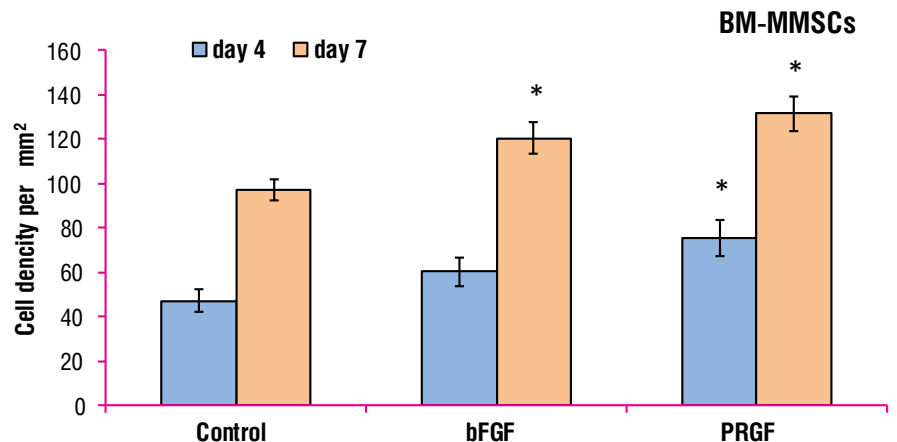

Fig. 3. Histograms of cell density in the defect of cell monolayer of cryopreserved BM-MMSCs cultured with bFGF or PRGF $(n=6, M \pm m)$. Note: * - differences are significant compared to control group, $p<0.05$

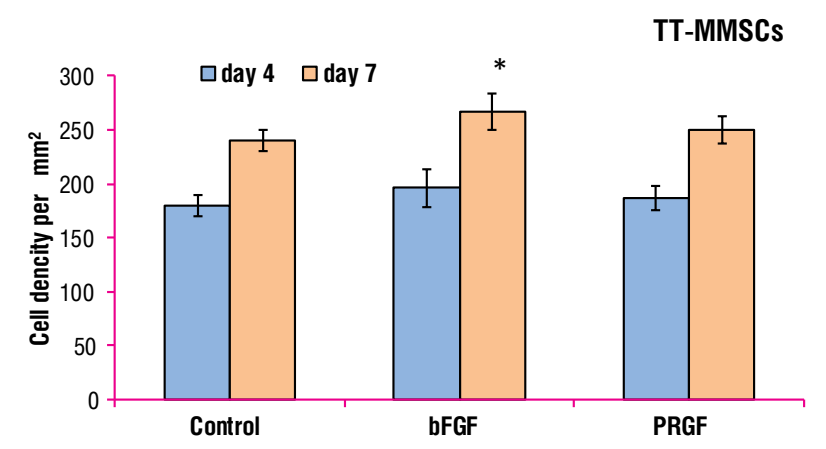

A

Fig. 4. Histograms of cell density in the defect zone of cell monolayer of cryopreserved TT-MMSCs cultured with bFGF or PRGF $(n=6, M \pm m)$. Note: ${ }^{*}$ - differences are significant compared to control group, $p<0.05$.

morpho-functional characteristics is possible due to the application of growth factors. The latter are able to regulate cell functions in an autocrine or paracrine ways. They initiate intracellular cascades of the signal transduction while tyrosine kinase receptor is binding to the cell surface. It was shown that bFGF, PDGF, and IGF-1 take an active part in the chemotaxis, proliferation and differentiation of the tendon cells, as well as in the production of extracellular matrix and regeneration. The use of bFGF can accelerate the healing of the damaged tissue of the popliteal tendon, most likely by stimulating the proliferation of fibroblasts, activating the synthesis of collagen and increasing the cell density in the supraclavicle tendons [30]. Other studies in vitro and in vivo have shown that bFGF also promotes angiogenesis and regulates cell migration in the tendon [31].

An alternative way of obtaining a set of growth factors involved in the regulation of cell functions may be the use of PRGF. Results of Anitua E. et al. indicate that application of PRGF stimulates the migration of tenocytes and synovial fibroblasts by 231.8 and $380.7 \%$ respectively, compared with native non-stimulated cells [32]. In addition to the cell migration ability, PRGF significantly increases the proliferation and adhesion of fibroblasts to the collagen type I matrix [33]. In in vitro experiments, PRGF also increases proliferation, migration, and chemotaxis of osteoblasts. In addition, PRGF significantly enhances the autocrine expression of proangiogenic factors (VEGF, HGF) and markers of osteoblastic activity (procolagen I, osteocalcin, alkaline phosphatase) [34].

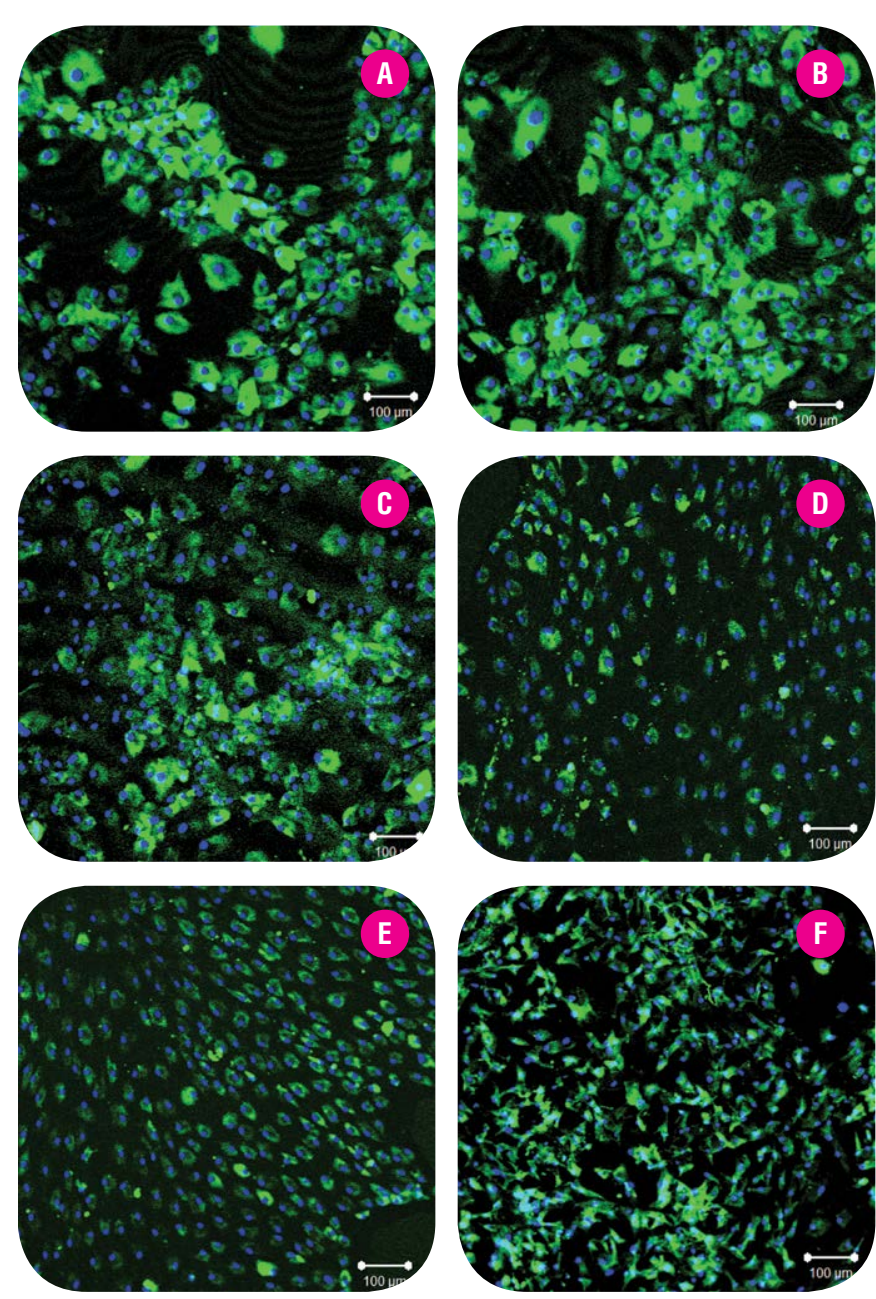

A Fig. 5. Microphotographs of BM-MMSCs (A-C) and TT-MMSCs (D-F) cultures on the $10^{\text {th }}$ day of cultivation: control $(\mathbf{A}, \mathbf{D})$, addition of $\mathrm{bFGF}(\mathbf{B}, \mathbf{E})$, addition of PRGF (C, F). Fluorescence microscopy, immunocytochemical staining for collagen type I (green), nuclei stained by DAPI (blue).

Consequently, to optimize the proliferative activity of cells, one can use both separate growth factors and their combinations. We have shown that in the case of BM-MMSCs, the application of PRGF leads to an increase in their proliferative and migration activity, which is combined with a decrease in the relative number of cells that produce collagen type I. When in TT-MMSCs culture, on the contrary, bFGF activates proliferation and cell migration as compared to control without adding growth factor to the culture medium.

The study should be considered as one of the attempts to determine the optimal potential source of MMSCs in combination with growth factors for application in regenerative medicine. Although in most cases the mechanisms by which transplanted cells stimulate the regeneration of damaged tissues are currently underdeveloped, the results contribute to their understanding and may be useful in the development of therapeutic strategies for a variety of the tendon tissue diseases. 


\section{CONCLUSION}

1. Cultures of cryopreserved stromal cells derived from bone marrow or tendon tissues of rats retain the ability to proliferate, migrate and produce collagen type I in vitro.

2. The application of plasma rich in growth factors contributes to the increase in the proliferation and migration ability of cryopreserved bone marrow-derived MMSCs along with a decrease in the relative number of cells that express collagen type I.

3. Cultures of cryopreserved tendon tissue-derived MMSCs exhibit greater sensitivity to the influence of the fibroblast growth factor than that of plasma rich in growth factors that manifests itself in increasing the ability of cells to proliferation and migration.

\section{REFERENCES}

1. Tozer S, Duprez D. Tendon and ligament: development, repair and disease. Birth Defects Res C Embryo Today. 2005; 75(3): 226-236.

2. Kyryk VM, Butenko GM. Stvolovye kletki iz zhirovoy tkani: osnovnye kharakteristiki i perspektivy klinicheskogo primeneniya v regenerativnoy meditsine (obzor literatury) [Stem cells from adipose tissue: the main characteristics and perspectives of clinical use in regenerative medicine (review)]. Zhurnal Akademiï medichnikh nauk Ukraiini - Journal of the Academy of Medical Sciences of Ukraine. 2010; 16(4): 576-604. [In Russian]

3. Volkova N, Yukhta M, Goltsev A. Cryopreserved Mesenchymal Stem Cells Stimulate Regeneration in an Intervertebral Disc. Biomedicines. 2015; 3(3): 237-247.

4. Rybachuk OA, Kyryk VM, Poberezhny PA, et al. Effect of the bone marrow multipotent mesenchimal stromal cells to the neural tissue after ischemic injury in vitro. Cell and Organ Transplantology. 2014; 2(1): 74-78.

5. Volkova NA, Yukhta MS, Yurchuk TA, et al. Multipotent mesenchymal stromal cells of bone marrow in therapy of chronic inflammation of murine ovaries. Biotechnologia Acta. 2014; 7(5): 35-42.

6. Ra J, Kang S, Shin S. Stem cell treatment for patients with autoimmune disease by systemic infusion of culture expanded autologous adipose tissue derived mesenchymal stem cells. J Transl Med. 2011; 9(1): 181-198.

7. Hegyi B, Sagi1 B, Kovacs J. Identical, similar or different? Learning about immunomodulatory function of mesenchymal stem cells isolated from various mouse tissues: bone marrow, spleen, thymus and aorta wall. Int Immunology. 2010; 22(7): 551-559.

8. Graham R. Tendinopathy - from basic science to treatment. Nature Clinical Practice Rheumatology. 2008; 4(2): 82-89.

9. Du M, Zhu T, Duan $X$, et al. Acellular dermal matrix loading with bFGF achieves similar acceleration of bone regeneration to BMP-2 via differential effects on recruitment, proliferation and sustained osteodifferentiation of mesenchymal stem cells. Mater Sci Eng C Mater Biol Appl. 2016; 70(1): 62-70.

10. Bocelli-Tyndall C, Zajac $P$, Maggio N, et al. Fibroblast growth factor 2 and platelet-derived growth factor, but not platelet lysate, induce proliferation-dependent, functional class II major histocompatibility complex antigen in human mesenchymal stem cells. Arthritis Rheum. 2010; 62(12): 3815-3825.

11. Chan BP, Fu SC, Qin L, et al. Effects of basic fibroblast growth factor (bFGF) on early stages of tendon healing: a rat patellar tendon model. Acta Orthopaedica Scandinavica. 2000; 71(5): 513-518.

12. Molloy T, Wang Y, Murrell GAC, Molloy T. The roles of growth factors in tendon and ligament healing. Sports Medicine. 2003; 33(5): 381-394.

13. Ehrenfest D, Rasmusson L, Albrektsson T. Classification of platelet concentrates: from pure platelet-rich plasma (P-PRP) to leucocyte- and platelet-rich fibrin (L-PRF). Trends Biotechnol. 2009; 27(3): 158-167.

14. Ehrenfest D, Bielecki T, Mishra A, et al. In search of a consensus terminology in the field of platelet concentrates for surgical use: platelet-rich plasma (PRP), plateletrich fibrin (PRF), fibrin gel polymerization and leukocytes). Curr Pharm Biotechnol. 2012; 13(7): 1131-1137.

15. Anitua E, Sanchez M, Merayo-Lloves J, et al. Plasma rich in growth factors (PRGF-Endoret) stimulates proliferation and migration of primary keratocytes and conjunctival fibroblasts and inhibits and reverts TGF- $\beta 1$-induced myodifferentiation). Investigative ophthalmology \& visual science. 2011; 52(9): 6066-6073.

16. Nishiyama K, Okudera T, Watanabe $T$, et al. Basic characteristics of plasma rich in growth factors (PRGF): blood cell components and biological effects). Clin Exp Dent Res. 2016; 2(2): 96-103.

17. Anitua E. Plasma rich in growth factors: preliminary results of use in the preparation of future sites for implants. International journal of Oral and maxillofacial Implants. 1999; 14(4): 529-535.

18. Sanchez M, Anitua E, Azofra J, et al. Comparison of surgically repaired Achilles tendon tears using platelet-rich fibrin matrices. Am J Sports Med. 2007; 35(2): $245-251$.

19. Sanchez M, Anitua E, Azofra J, et al. Intra-articular injection of an autologous preparation rich in growth factors for the treatment of knee OA: a retrospective cohort study. Clin Exp Rheumatol. 2008; 269(5): 910-913

20. Costa $M A, W u C$, Pham BV, et al. Tissue engineering of flexor tendons: optimization of tenocyte proliferation using growth factor supplementation. Tissue engineering 2006; 12(7): 1937-1943.

21. Anitua E, Sanchez M, Orive G, et al. The potential impact of the preparation rich in growth factors (PRGF) in different medical fields. Biomaterials. 2007; 28(31): 45514560 .

22. Anitua E, Pino A, Orive G. Plasma rich in growth factors promotes dermal fibroblast proliferation, migration and biosynthetic activity. J Wound Care. 2016; 25(11): 680-687.

23. Volkova NA, Yukhta MS, Goltsev AN. Morphological and functional characteristics of cryopreserved multipotent mesenchymal stromal cells from bone marrow, adipose tissue and tendons. Cell and Organ Transplantology. 2016; 4(2): 200-205.

24. Council of Europe [France]. European convention for the protection of vertebrate animals used for experimental and other scientific purposes. Strasbourg, 18.III.1986, http://conventions.coe.int/treaty/en/Treaties/Word/123.doc

25. Volkova NA, Goltsev AN. Cryopreservation effect on proliferation and differentiation potential of cultured chorion cells. CryoLetters. 2015; 36(1): 25-29.

26. Song $G$, Ju $Y$, Soyama $H$. Growth and proliferation of bone marrow mesenchymal stem cells affected by type I collagen, fibronectin and bFGF. Materials Science and Engineering: 2008; 28(8): 1467-1471

27. Mossman T. Rapid colorimetric assay for cellular growth and survival: application to proliferation and cytotoxicity assays. J Immunol Methods. 1983; 65(1-2): 55-63. 
28. Vigano M, Orfei CP, Colombini A, et al. Different culture conditions affect the growth of human tendon stem/progenitor cells (TSPCs) within a mixed tendon cells (TCs) population. Journal of experimental orthopedics. 2017; 4(1): 8.

29. Maffulli N, Ewen SW, Waterston SW, et al. Tenocytes from ruptured and tendinopathic achilles tendons produce greater quantities of type III collagen than tenocytes from normal achilles tendons: an in vitro model of human tendon healing. Am J Sports Med. 2000; 28(4): 499-505.

30. Chan BP, Fu S, Qin L, et al. Effect of basic fibroblast growth factor (bFGF) on early stages of tendon healing: a rat patellar tendon model. Acta Orthop Scand. 2000; 71: 513.

31. Folkman J, Klagsbrun M. Angiogenic factors. Science. 1987; 235(4787): 442-447.

32. Anitua $E$, Sanchez $M$, de la Fuente $M$, et al. Plasma rich in growth factors (PRGF-Endoret) stimulates tendon and synovial fibroblasts migration and improves the biological properties of hyaluronic acid. Knee Surg Sports Traumatol Arthrosc. 2012; 20(9): 1657-1665.

33. Anitua $E$, Troya $M$, Orive $G$. Plasma rich in growth factors promote gingival tissue regeneration by stimulating fibroblast proliferation and migration and by blocking transforming growth factor- $\beta 1$-induced myodifferentiation. Orive Periodontol. 2012; 83(8): 1028-1037.

34. Anitua $E$, Tejero $R$, Zalduendo $M M$, et al. Plasma rich in growth factors promotes bone tissue regeneration by stimulating proliferation, migration, and autocrine secretion in primary human osteoblasts. J Periodontol. 2013; 84(8): 1180-1190.

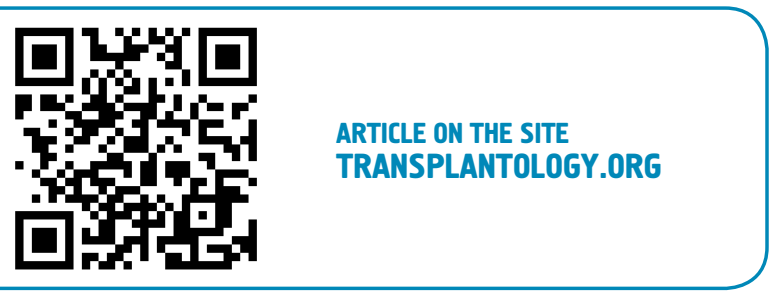

The authors indicate no potential conflicts of interest.

Received: September 09, 2017

Accepted: November 30, 2017

The study was performed with support from the target complex multidisciplinary program of scientific research of NAS of Ukraine «Molecular and cellular biotechnology for medicine, industry and agriculture» the contract number 2.2.6.94. 